\title{
Theraupetic sebagai Konsep Desain Fasilitas untuk Lansia Dimensia di Sidoarjo, Jawa Timur
}

\author{
Dimas Audri Yanuar ${ }^{1}$, Sigit Hadi Laksono ${ }^{2}$ \\ ${ }^{1}$ Jurusan Arsitektur, Fakultas Teknik Sipil dan Perencanaan, Institut Teknologi Adhi Tama Surabaya \\ ${ }^{2}$ Jurusan Arsitektur, Fakultas Teknik Sipil dan Perencanaan, Institut Teknologi Adhi Tama Surabaya \\ Email: 1dimasaudril@gmail.com
}

\begin{abstract}
Elderly (elderly) is someone who is categorized in an age that reaches the age of 60 years or more. With age the physical ability and motor ability of a person also decreases. Reporting from the data of the demographic affairs office of Sidoarjo district in November 2019, the number of elderly population reached 270,881 inhabitants. With increasing age, the level of memory in the brain decreases which result in senility (dementia). Generally, the elderly are placed in a nursing home where their daily activities are limited so that elderly people in nursing home experienced stress and cause dementia to get worse. Dementia is considered prevalent in most communities, so the people with dementia are not early detected. Dementia is divided into 4 types, namely: Alzheimer, Lewy Body, Vascular and Parkinson. Each type of dementia has different treatment so the therapy process can run effectively. In the process of planning and designing a therapeutic complex for elderly people with dementia in the Sidoarjo District are applying the rules of behavior architectural themes in which each dementia complex has different facilities and it's assessed based on the user. Also, helping government programs written in the Sidoarjo district regional regulation number 4 of 2010 regarding Elderly Welfare, The government is obliged to provide services and social protection for the elderly so that they can actualize and enjoy a decent standard of living.

Keywoards : Theraupetic, Elderly, Dementia
\end{abstract}

\begin{abstract}
Abstrak. Lansia (lanjut usia) adalah seseorang yang dikategorikan dalam usia yang mencapai usia 60 tahun atau lebih. Dengan seiring bertambahnya usia, kemampuan fisik dan kemampuan motorik seseorang juga menurun. Dilansir dari data dispenduk kabupaten sidoarjo November 2019, jumlah penduduk lansia mencapai 270.881 jiwa. Dengan bertambahnya usia, tingkat memori dalam otak akan semakin menurun yang mengakibatkan kepikunan (demensia). Umumnya, lansia ditempatkan pada sebuah panti jompo yang mana kegiatan sehari-harinya dibatasi sehingga banyak lansia yang berada di dalam panti jompo mengalami stress dan menyebabkan penyakit demensia semakin memburuk. Kepikunan dianggap hal lazim pada sebagian besar masyarakat, sehingga penderita demensia tidak terdeteksi sejak dini. Demensia dibagi menjadi 4 jenis, yaitu : Alzheimer, Lewy Body, Vaskuler dan Parkinson. Setiap jenis demensia memiliki penanganan yang berbeda agar proses terapi bisa berjalan dengan efektif. Pada proses perencanaan dan perancangan kompleks therapeutic untuk lansia demensia di kabupaten sidoarjo menerapkan kaidah-kaidah tema arsitektur perilaku dimana pada setiap kompleks demensia memiliki fasilitas yang berbeda dan dikaji berdasarkan pengguna. Serta, membantu program pemerintah yang tertulis berdasarkan peraturan daerah kabupaten Sidoarjo Nomor 4 Tahun 2010 tentang Kesejahteraan Lanjut Usia, pemerintah berkewajiban memberikan pelayanan dan perlindungan sosial bagi lansia agar mereka dapat mewujudkan dan menikmati taraf hidup yang layak.
\end{abstract}

Kata Kunci : Theraupetic, Lansia, Demensia

\section{Pendahuluan}

Lansia (lanjut usia) adalah seseorang yang dikategorikan dalam usia yang mencapai usia 60 tahun atau lebih. Dengan seiring bertambahnya usia, kemampuan fisik dan kemampuan motorik seseorang juga menurun. Dilansir dari data dispenduk kabupaten sidoarjo November 2019, jumlah penduduk lansia mencapai 270.881 jiwa angka ini terus mengalami peningkatan dari tahun 2017 hingga 2019 .

Seiring dengan bertambahnya usia, permasalahan yang muncul pada lansia adalah kepikunan. Kepikunan dianggap hal lazim pada sebagian besar masyarakat sehinga penderita demensia tidak 
terdeteksi sejak dini. Umumnya, lansia banyak ditempatkan di panti jompo dan kebanyakan mereka mengalami demensia. Respon dari lansia berbeda beda mulai dari senang, tidak nyaman dan stress namun, kebanyakan mereka mengalami stress karena aktifitas mereka dibatasi dan mereka tidak dapat melakukan aktifitas seperti biasanya dirumah. Demensia atau yang sering juga disebut pikun, merupakan penyakit yang paling banyak di alami oleh lansia yang mengakibatkan penurunan memori serta mengalami perubahan perilaku dan cara bicara. Demensia memiliki beberapa tipe, setiap tipe demensia memiliki penanganan yang berbeda sehingga penderita harus ditangani dengan tepat sesuai dengan jenis demensia yang dideritanya.

Maka, pada proyek tugas akhir ini akan dirancang kompleks therapeutic untuk lansia demensia dengan tema arsitektur perilaku dimana pada proses penyembuhan demensia ditinjau berdasarkan jenis demensia serta penanganan yang tepat. Proyek tugas akhir ini bertujuan membantu program pemerintah Sidoarjo yang tertulis dalam perda Nomor 4 Tahun 2010 tentang Kesejahteraan Lanjut Usia menetapkan pemerintah berkewajiban memberikan pelayanan dan perlindungan sosial bagi lansia agar mereka dapat mewujudkan dan menikmati taraf hidup yang layak.

\subsection{Tinjauan Pustaka}

Menurut Donna P. Duerk, 1993 Bahwa manusia dan perilakunya adalah bagian dari system yang menempati tempat dan lingkungan, sehingga perilaku dan lingkungan tidak dapat dipisahkan secara empiris. Karena itu perilaku manusia sealu terjadi pada suatu tempat dan tidak dapat dievaluasi secara keseluruhan tanpa pertimbangan faktor-faktor lingkungan.

Therapeutic adalah hasil pembentukan disekitar manusia yang bersifat pemulihan atau recovery bagian tubuh yang telah terganggu. Hal ini secara lansung lingkungan berkontribusi dalam proses terapi (Emil Salim, 1976).

Menurut World Health Organisation (WHO), lansia adalah seseorang yang telah memasuki usia 60 tahun keatas. Lansia merupakan kelompok umur pada manusia yang telah memasuki tahapan akhir dari fase kehidupannya. Kelompok yang dikategorikan lansia ini akan terjadi suatu proses yang disebut Aging Process atau proses penuaan.

Demensia adalah kumpulan penyakit dengan gejala-gejala yang mana mengakibatkan perubahan pada pasien dalam cara berpikir dan berinteraksi dengan orang lain. Seringkali, memori jangka pendek, pikiran, kemampuan berbicara dan kemampuan motorik terpengaruh. Beberapa bentuk demensia mengubah kepribadian pasien. Penderita demensia akan kehilangan kemampuan tertentu dan pengetahuannya yang telah didapatkan sebelumnya (Elvira, Sylvia D, et al. 2010).

\subsection{Metode Penelitian}

Jenis metode penelitian yang digunakan adalah penelitian deskriptif kualitatif, penelitian ini berkaitan dengan pengumpulan data untuk memberikan gambaran tentang terapi demensia, umumnya dilakukan dengan metode survey tentang komplek demensia, wawancara, pengamatan, studi kasus, studi korelasi, dan sebagainya. Dengan pengumpulan data untuk memberikan gambaran tentang suatu gejala. Adapun teknik metode yang dipakai untuk mendukung dalam penelitian ini adalah : Metode interview, Metode literature, Metode dokumentasi.

\section{Pembahasan}

Pembahasan ini menyajikan proses perencanaan konsep desain, mulai dari pengumpulan objek studi banding, penyusunan program ruang, analisa site, program rancangan, hingga hasil berupa konsep rancangan dari Fasilitas untuk Lansia Dimensia.

\subsection{Studi Banding}

Hasil Observasi studi banding lapangan dan literature menghasilkan data yang dapat digunakan untuk merancangan dan membuat program ruang serta desain pada Kompleks Therapeutic Untuk Lansia Demensia. Studi banding lapangan dilakukan di Panti Werdha Hargodedali Surabaya dan Rumah Usiawan Panti Surya Surabaya, Studi literature menggunakan Graha Wedha AUSSI Kusuma Lestari Depok dan De Hogeywek Dementia Village Nedherlands. 


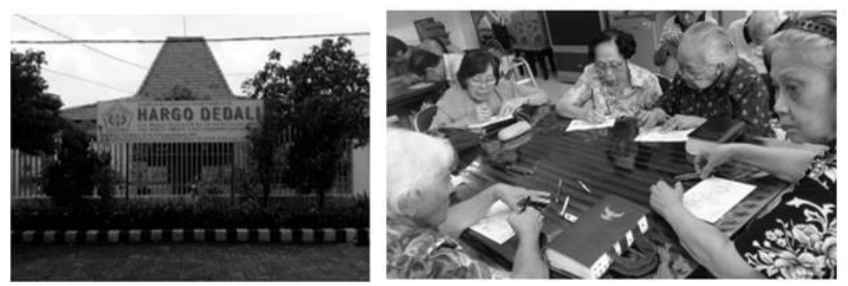

Gambar 1. Panti Werdha Hargodedali (Kiri) dan Rumah Usiawan Panti Surya (Kanan)

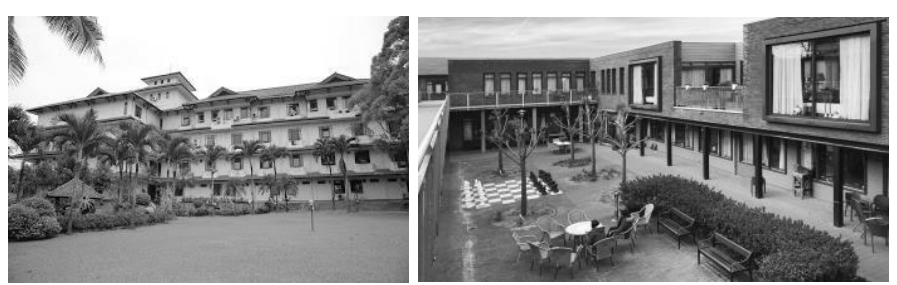

Gambar 2. Graha Werdha AUSII Kusuma Lestari (Kiri) dan De Hogeywek Dementia Village (Kanan)

Telaah studi banding lapangan dan literatur tersebut dapat menjadi acuan dan contoh dalam merancang dengan melakukan perbaikan agar menghasilkan rancangan yang lebih baik dan sesuai dengan kebutuhan.

\subsection{Program Ruang}

Setelah mengakaji pada Alzheimers Assosiation Research di bab kajian teori serta studi literature De hogeywek dementia village menghasilkan ruang sebagai berikut :

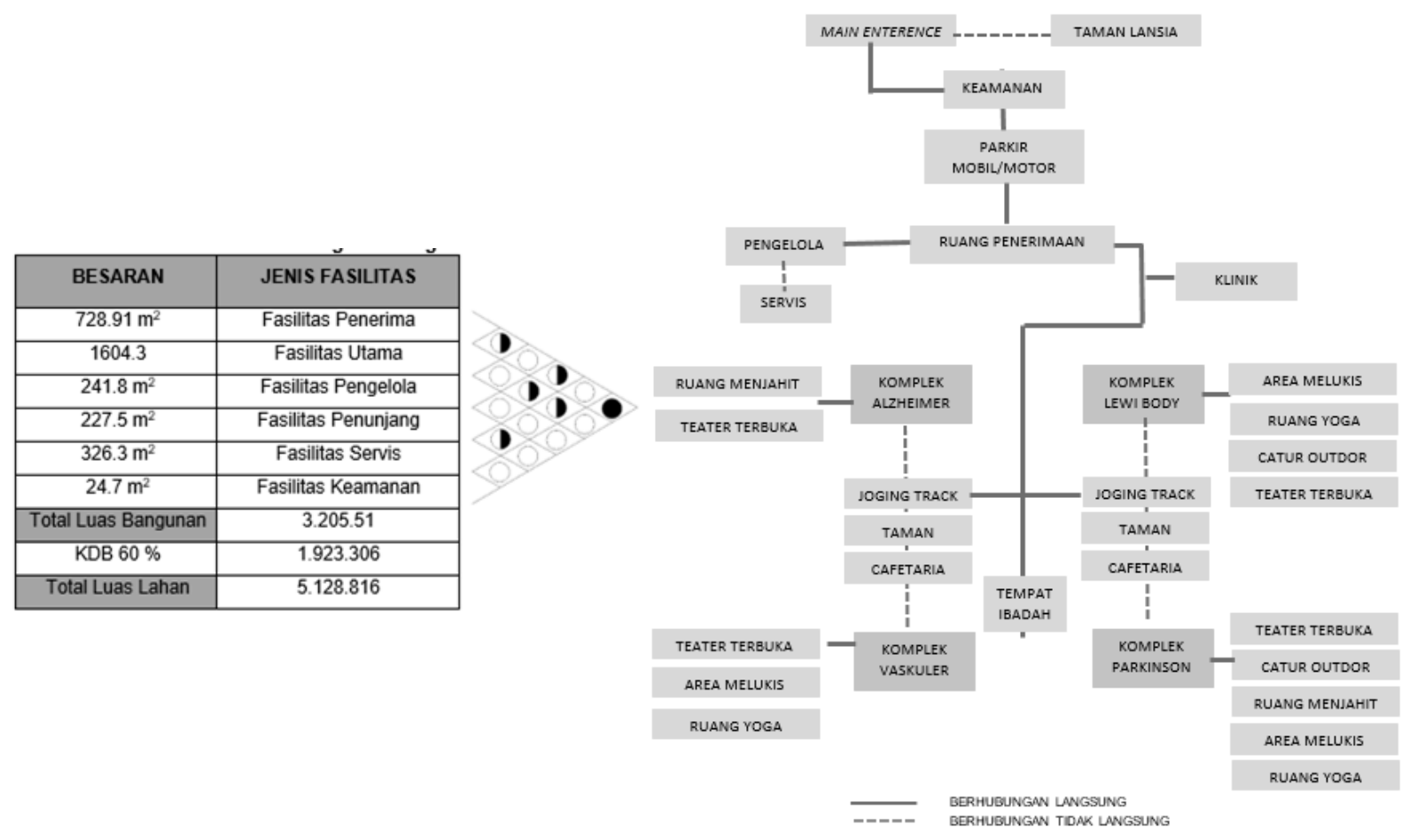

Gambar 3. Total Besaran Ruang Keseluruhan (Kiri) dan Organisasi Ruang (Kanan)

\subsection{Analisa Site}

Tapak terpilih pada Jalan Jaksa Agung Suprapto, Kelurahan Sidokumpul, Kecamatan Sidoarjo, Kabupaten Sidoarjo seluas 1.5 Ha. Perletakan site berada di pusat kota Sesuai data dari RTRW (Rencana Tata Ruang Wilayah) Kota Sidoarjo Tahun 2009 - 2029, Perwilayahan sebagaimana yang dimaksud dalam pasal 23 huruf C. Lokasi site termasuk kedalam kawasan SSWP (Sub Satuan Wilayah 
Pengembangan) II meliputi sebagian wilayah Kecamatan Sidoarjo, sebagian Kecamatan Buduran, dan sebagian Kecamatan Candi, dengan fungsi utama Permukiman, Pusat pemerintahan, Perdagangan dan jasa dengan pusat pertumbuhan berada di Kawasan Sidoarjo.

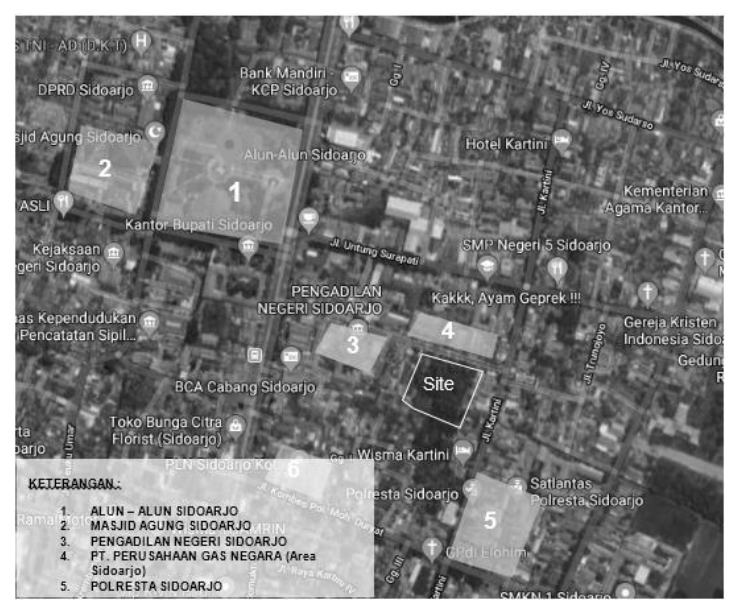

Gambar 4. Lokasi Site

Analisis zonifikasi dari site rancangan terbentuk berdasarkan kebutuhan tatanan massa dari perencanaan dan perancangan Kompleks Therapeutic Untuk Lansia Demensia Di Kabupaten Sidoarjo tersebut. Dari gambar yang disajikan diatas dapat disimpulkan jika semua fasilitas pada analisa kebutuhan ruang sebelumnya, dikelompokkan berdasarkan zonifikasi umum (publik, semipublik, hingga privat) dan ditransformasikan sesuai dengan tatanan massa dari bangunan.

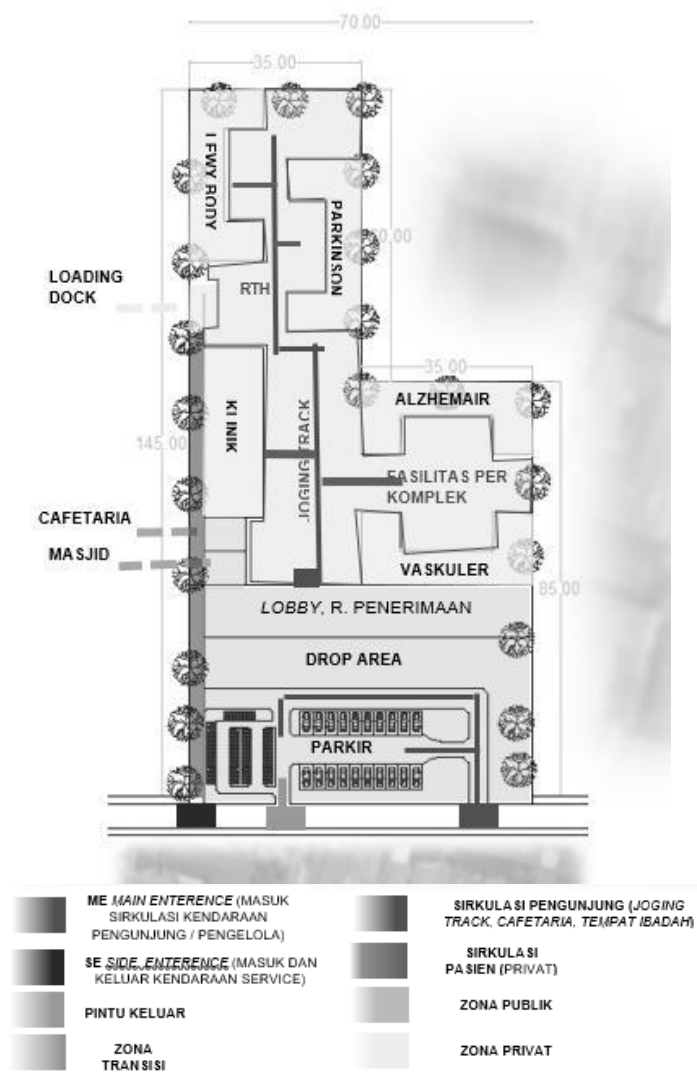

Gambar 5. Kesimpulan Tatanan Lahan

\subsection{Program Rancangan}


Program rancangan terdiri dari program rancangan tatanan lahan, program rancangan bentuk, dan program rancangan ruang, yang dapat dilihat pada gambar-gambar berikut:

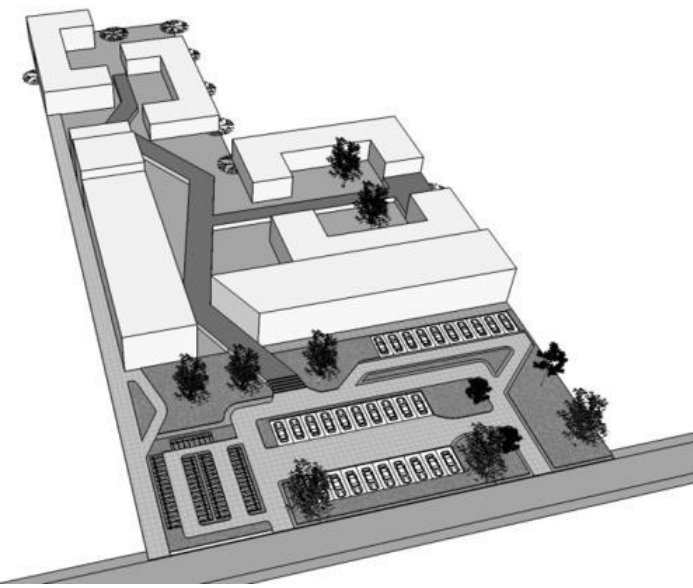

Gambar 6. Program Rancangan Tatanan Lahan

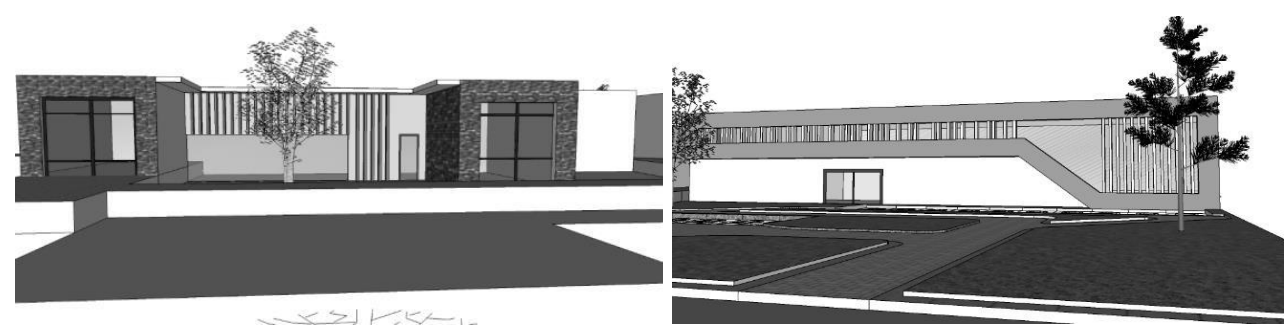

Gambar 7. Program Rancangan Bentuk

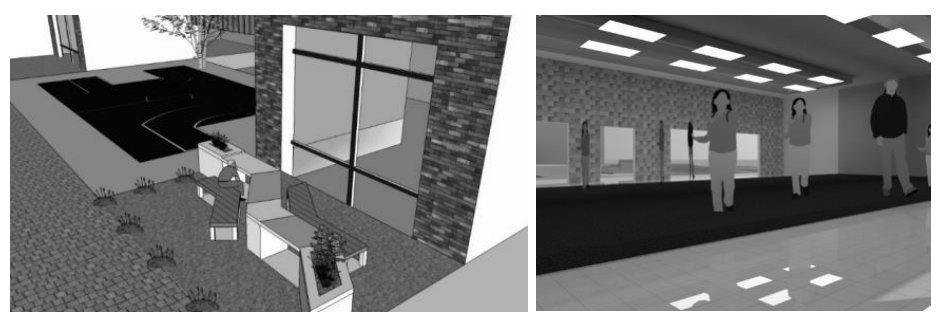

Gambar 8. Program Rancangan Ruang

\subsection{Konsep Rancangan}

Konsep rancangan ini menceritakan mulai dari penarikan tema, mengerucut ke makro konsep "simiotica", hingga mikro konsep "cluster dementia", "simiotica qualisign", dan "healing".

\subsubsection{Tema Arsitektur Perilaku}

Sebuah desain yang metode perancanganya melalui pendekatan perilaku dari suatu objek ditentukan. Seperti menunjukan manusia dalam aksinya berkaitan dengan aktifitas manusia secara fisik berupa interaksi manusia dengan sesamanya ataupun dengan lingkunganya.

\subsubsection{Makro Konsep "Simiotika"}

Menciptakan bangunan yang nyaman dan ramah terhadap pengguna dengan menciptakan sebuah tanda yang dapat mendefinisikan suatu hal yang ujungnya dapat memudahkan pengguna sekaligus sebagai sarana penyembuhan berdasarkan jenis penyakit demensia yang diderita.

\subsubsection{Mikro Konsep Tatanan lahan "Cluster Dementia"}

Menciptakan bentuk tatanan masa yang sesuai dengan proses terapi berdasarkan kriteria demensia yang ditentukan. 


\subsubsection{Mikro Konsep Bentuk "Simiotica Qualisign"}

Menciptakan bentuk berdasarkan jenis demensia yang dapat dimanfaatkan menjadi tanda berdasarkan sifatnya. Misalnya sifat warna biru yang merupakan penuh ketenangan dapat digunakan pada salah satu kriteria demensia.

\subsubsection{Mikro Konsep Ruang "Healling”}

Menciptakan ruang yang menyenangkan dan bersifat sebagai proses penyembuhan pasien berdasarkan kajian dari berbagai jenis demensia yaitu : Alzheimer, Vaskuler, Lewy Body, dan Parkinson.

\section{Kesimpulan}

Perencanaan desain fasilitas untuk lansia demensia ini nantinya akan diarahkan untuk menggunakan tema arsitektur perilaku dengan konsep berupa arsitektur theraupetic. Adapun konsep makro yang diambil adalah simiotika, dan didetailkan ke dalam konsep micro cluster dementia pada tatanan lahan, simiotica qualisign pada bentukan desain, dan healing pada desain ruang. Hal ini dilakukan untuk menjawab kebutuhan dari penanganan lansia dengan demensia. Tujuan dari proyek ini adalah tidak lain untuk membantu program pemerintah Sidoarjo yang tertulis dalam perda Nomor 4 Tahun 2010 tentang Kesejahteraan Lanjut Usia menetapkan pemerintah berkewajiban memberikan pelayanan dan perlindungan sosial bagi lansia agar mereka dapat mewujudkan dan menikmati taraf hidup yang layak .

\section{Referensi}

Dharma, Agus. Semiotika Dalam Arsitektur. Universitas Gunadarma. Diakses dari: http://staffsite.gunadarma.ac.id/agus_dh/

Basics of Alzheimer's Disease, Rev. 2016. Alzheimer's Association

Broadbent, Geoffrey. 1980. Signs, Symbols, and Architecture. New York: John Willey \& Sons.

Eveline Sabrina Tampubolon., (2008). "Rumah Tinggal sebagai Lingkungan Therapeutic bagi Lanjut Usia". Universitas Indonesia. Diakses dari: http://lib.ui.ac.id/file?file=digital/125113050805.pdf

Havet, Jackues (ed.). 1978. Main Trends of Research in Social and Human Science. New York: Mouton Publisher Unesco.

Fox, Michael J. 2018. Foundation for Parkinson's Research. Alzheimers Association

Patriyani, Ros E. H. 2009. "Perbedaan Karakteristik Lansia dan Dukungan Keluarga Terhadap Tipe Demensia pada Lansia di Wilayah Kerja Puskesmas Gatak Sukoharjo". FIK-UI.12-21. Retrivied from Ros\%20Endah\%20Happy\%20Patriyani.pdf

Wicaksono, Satrio Indra. "Locul Potrivit - Character Building Center di Kaliurang" http://ejournal.uajy.ac.id/12875/

Pambudi, Tahta R. M. 2017. Yogyakarta: Fk Universitas Muhammadiyah Yogyakarta. Diakses dari: http://repository.umy.ac.id/handle/123456789/12584

Tandali, A. N. dan P. P. Egam. 2011. "Arsitektur Berwawasan Perilaku (Behaviorisme)". Media Matrasain, 8(1), 55-59. Diakses dari: https://ejournal.unsrat.ac.id/index.php/index/search/search?query=arsitektur+perilaku\&sear chJournal

Universal Dictionary \& Thesaurus. USA. Pg. 479

Vascular Dementia, Update. 2019. Alzheimer's Association

McKeith, Ian dan Zuzana Walker. 2016. "What is dementia with Lewy bodies (DLB)?". Old Age Psychiatry-Campus for Ageing and Vitality. Newcastle: Newcastle University

Zoest, Aart van. 1978. Semiotika, Pemakaiannya, Isinya, dan Apa yang Dikerjakan dengannya (terjemahan). Bandung: Unpad.

Adisasmita, Rahardjo. 2013. Pembangunan Kawasan dan Tata Ruang. Yogyakarta: Graha Ilmu

Sugandhy, Aca dan Rustam Hakim. 2007. Prinsip Dasar Kebijakan Pembangunan Berkelanjutan Berwawasan Lingkungan. Jakarta: PT Bumi Aksara 
Pamungkas, Aji, dan Dian Rahmawati. 2017. Perencanaan Kawasan Pesisir Terpadu di Indonesia. Yogyakarta: Teknosain 
